\title{
Short communication \\ A differential phenotypic expression of a divergent spindle mutation in interspecific Brachiaria hybrids
}

\author{
Mariana Ferrari Felismino ${ }^{a}$, Maria Suely Pagliarini ${ }^{a, *}$, Cacilda Borges do Valle ${ }^{\mathrm{b}}$ \\ ${ }^{a}$ Department of Cell Biology and Genetics, State University of Maringá, 87020-900 Maringá, Paraná, Brazil \\ ${ }^{\mathrm{b}}$ Embrapa Beef Cattle, P.O. Box 154, 79002-970 Campo Grande, MS, Brazil
}

Received 12 March 2008; revised 7 April 2008; accepted 5 July 2008

\begin{abstract}
Several mutations are known to alter the normal progression of meiosis and can be correlated with defects in microtubule distribution. The $d v$ mutation affects the spindle organization and chromosomes do not converge into focused poles. Two Brachiaria hybrids presented the phenotypic expressions of $d v$ mutation but exhibited many more details in the second division. Bivalents were distantly positioned and spread over a large metaphase plate and failed to converge into focused poles. Depending on the distance of chromosomes at the poles, telophase I nuclei were elongated or the chromosomes were grouped into various micronuclei of different sizes in each cell. The first cytokinesis occurred. However, when there were micronuclei, a second cytokinesis immediately took place dividing the prophase II meiocytes into three or four cells. In each meiocyte, meiosis progressed to the second division. Slightly elongated nuclei or micronuclei were recorded in telophase II. After a third cytokinesis, hexads or octads were formed. Pollen grains of different sizes were generated. One of these hybrids presented a higher frequency of abnormal cells than when previously analyzed. The fate of these hybrids as genitors or as candidates for cultivars in the Brachiaria breeding program is discussed.
\end{abstract}

(C) 2008 International Federation for Cell Biology. Published by Elsevier Ltd. All rights reserved.

Keywords: Brachiaria; Breeding program; Forage grass; Interspecific hybrids; Meiotic mutation; Divergent spindle

\section{Introduction}

Meiosis is a crucial, highly conserved stage occurring during the sexual reproduction of all eukaryotes. A single round of DNA replication is combined with two successive divisions to form four haploid products that allow the process of reassortment and segregation of genetic information (Wilson and Yang, 2004), a process accurately controlled by a large number of stage-specific genes (Gottschalk and Kaul, 1974, 1980a,b; Baker et al., 1976; Golubovskaya, 1979, 1989).

Chromosome segregation is mediated by a complex superstructure of proteins - the spindle. The forces required for spindle assembly and movements have been attributed to microtubule dynamics (Endow, 1999). Microtubules are formed by polymeric self-organization of tubulin, which is

\footnotetext{
* Corresponding author. Tel./fax: +55 4432614957.

E-mail address: mspagliarini@uem.br (M.S. Pagliarini).
}

initiated at microtubule organizing centers. Microtubules organizing centers, comparable to centrosomes in animals, are not known in plants (Binarová et al., 2000). In plant meiocytes, microtubules initially appear around prometaphase chromosomes, indicating a chromatin mediated spindle assembly mechanism (Chan and Cande, 1998).

In higher plants, meiotic mutations disrupting the structure and function of the division spindle have been reported (Clark, 1940; Golubovskaya, 1979, 1989; Golubovskaya and Mashnenkov, 1981; Staiger and Cande, 1990, 1991; Golubovskaya et al., 1992; Taschetto and Pagliarini, 1993; Pagliarini et al., 1998; Shamina et al., 2000; Shamina, 2005). The more frequent mutation affecting spindle structure is the divergent spindle $(d v)$, reported in maize (Clark, 1940; Golubovskaya, 1979, 1989; Golubovskaya and Mashnenkov, 1981; Staiger and Cande, 1990, 1991; Golubovskaya et al., 1992; Shamina et al., 2000; Shamina, 2005), where spindle fibers do not converge to focused poles. This mutation was originally 
described by Clark (1940). Recently, Mendes-Bonato et al. (2006) reported the occurrence of a putative $d v$ mutation in an interspecific Brachiaria hybrid.

In all descriptions of the $d v$ mutation, the reports are centered in the first meiotic division because of the size of the cell. In the second division, the phenotypic expression of $d v$ is difficult to define in the two sister-cells of monocotyledoneous species. A cytological re-analysis of the cited Brachiaria hybrid collected in another year, and the analysis of a half-sib hybrid of it, revealed a clear phenotypic expression of this putative $d v$ mutation, allowing a better understanding of facts occurring in the second meiotic division and of its end products.

\section{Material and methods}

Cytological studies were carried out on two interspecific half-sib hybrids (HBGC306 and HBGC348) between Brachiaria ruziziensis and Brachiaria brizantha. The original female genitors in these hybrids were two artificially tetraploidized sexual accessions of B. ruziziensis (R41 and R44: $2 n=4 x=36$ ), which were crossed to a natural apomictic genotype of $B$. brizantha cv. Marandu (B140) $(2 n=4 x=36)$. These two hybrids are related through the male genitor and were produced by artificial pollination in the greenhouse at
Embrapa Beef Cattle Center (Campo Grande, State of Mato Grosso do Sul, Brazil) in 1988. Hybrid HBGC306 is sexual and HBGC348 is apomictic as determined by embryological analysis of embryo-sac structure using interference contrast microscopy on methylsalicilate-cleared ovaries (Young et al., 1979). These hybrids have excellent phenotypes from the forage standpoint and are under small plot agronomical evaluation.

Inflorescences for meiotic studies were collected from individual plants under free growth in the field and fixed in a mixture of ethanol 95\%, chloroform and propionic acid (6:3:2 $\mathrm{v} / \mathrm{v})$ during $24 \mathrm{~h}$ and stored under refrigeration until use. Microsporocytes were prepared by squashing and stained with $0.5 \%$ propionic carmine. More than 2300 pollen mother cells (PMCs) were analyzed in each hybrid. Cells were photographed with Kodak Imagelink - HQ, ISO 25 black and white film.

\section{Results and discussion}

Fig. 1 illustrates the meiotic behavior of spindle fibers in normal meiocytes, with chromosome: (i) aligning in a narrow metaphase plate in the center of the cell in metaphase I (Fig. 1a) and metaphase II (Fig. 1e); (ii) ascending towards the poles by spindle fibers convergence in anaphase I (Fig. 1b) and anaphase

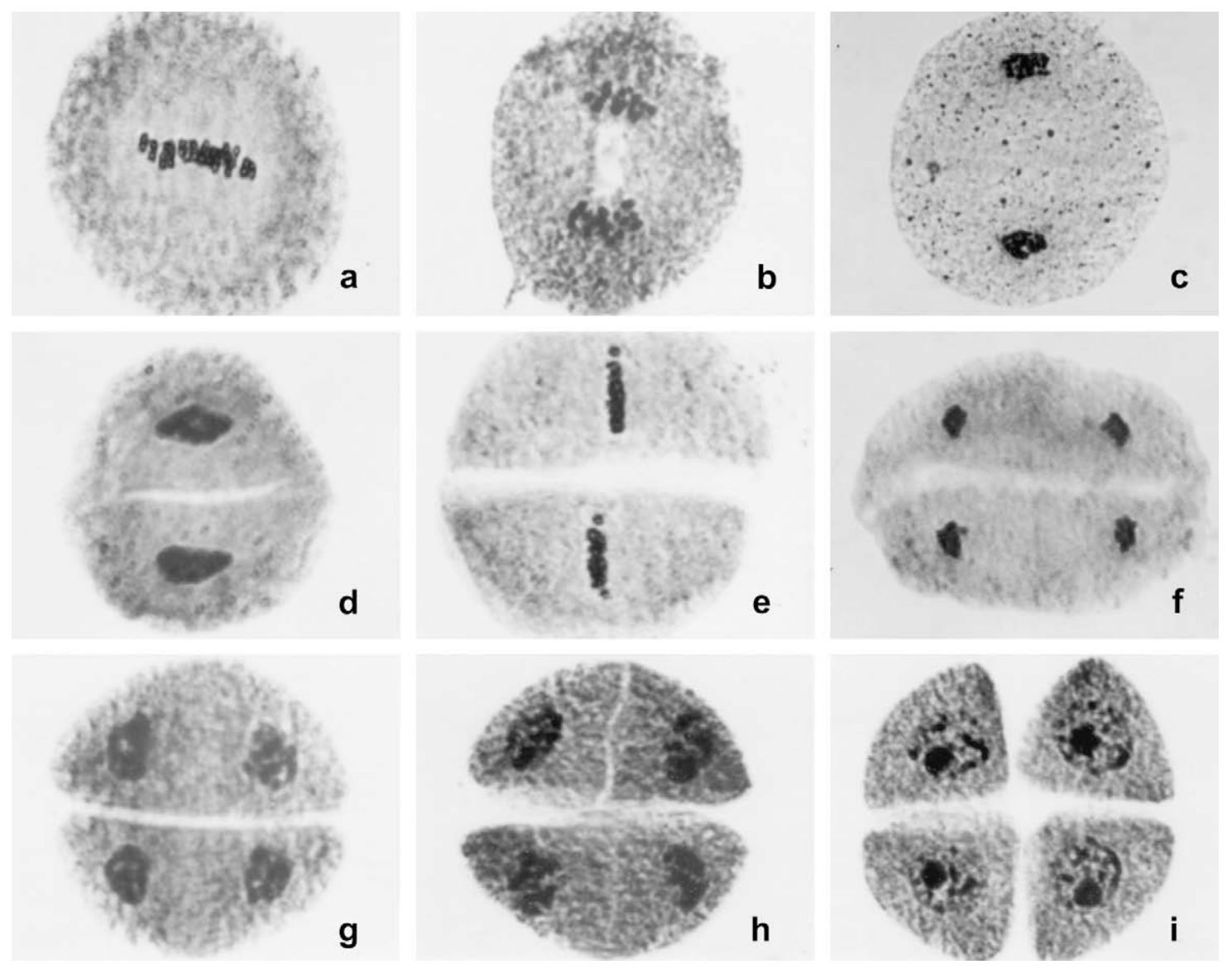

Fig. 1. Aspects of normal meiosis in Brachiaria. Meiocytes in metaphase I (a) and metaphase II (e) with a narrow metaphase plate. Anaphase I (b) and anaphase II (f) showing chromosome convergence to the poles. Telophase I (c), prophase II (d) and telophase II (g, h) with spherical nuclei. Tetrad of microspores (i) (Magnification: $400 \times$ ). 


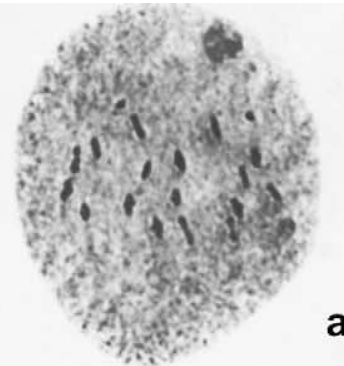

a
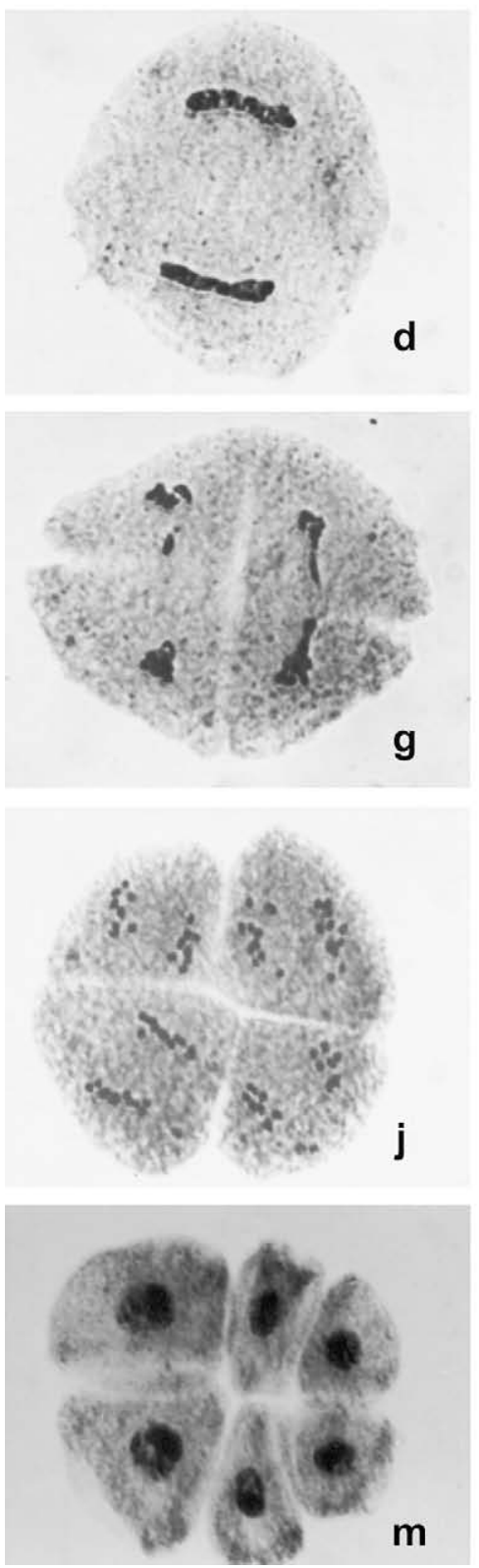
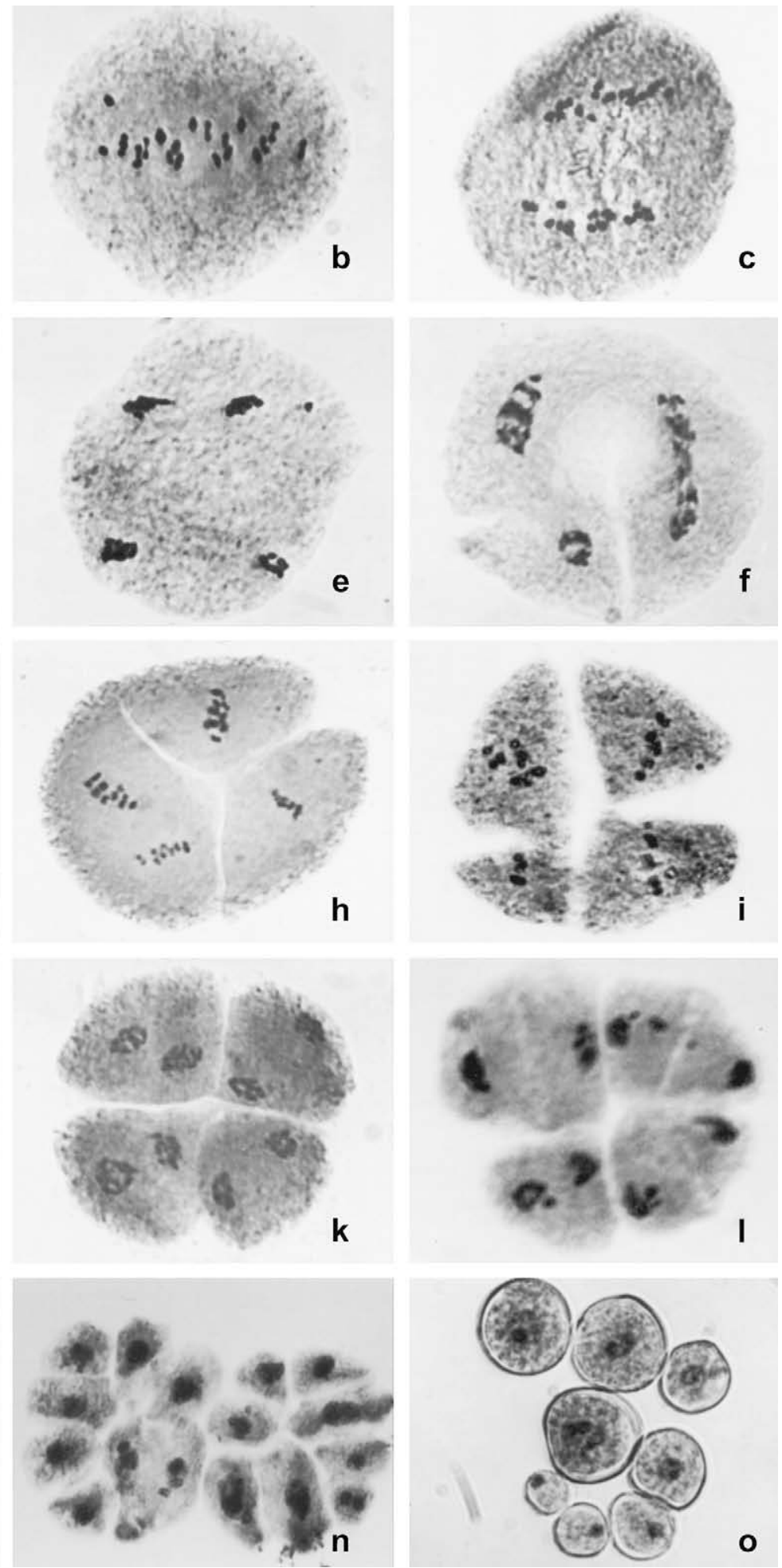

Fig. 2. Aspects of meiocytes with the abnormality: (a) meiocyte in prometaphase with 17 bivalents and one pair of univalents spread in the center of the cell with chromosomes in parallel orientation; (b) metaphase I with a broad metaphase plate and bivalents in parallel orientation; (c) anaphase I with chromosome ascending in parallel to the poles; (d) telophase I with elongated nuclei; (e) telophase I with micronuclei; (f) early prophase II with one elongated nuclei and two micronuclei; (g) telophase I with micronuclei. Notice in $\mathrm{f}$ and $\mathrm{g}$ the second cytokinesis separating the micronuclei; (h) metaphase II with three cells, and in one of them there are two metaphase plates; (i) metaphase II with four cells with different numbers of chromosomes in each one; (j) anaphase II with four cells; (k) telophase II with four cells; (1) telophase II with micronuclei resulting from absence of chromosome convergence; (m) hexad of microspores; (n) octad of microspores. Observe differences in the size of microspores; (o) eight pollen grains of different sizes (Magnification: $400 \times$ ). 
II (Fig. 1f); and (iii) forming spherical nuclei in telophase I (Fig. 1c), prophase II (Fig. 1d), and telophase II (Fig. 1g,h), culminating in a tetrad of haploid microspores (Fig. 1i).

According to Staiger and Cande (1991), in normal meiocytes, meiotic spindles, during both divisions, have highly focused poles and a predictable orientation within the cells and the anther locule. Cytokinesis follows each meiotic division, and is accomplished by a typical phragmoplast that is initiated in the spindle midzone during late anaphase and telophase. The array of parallel phragmoplast microtubules propagates centrifugally, forming a ring around the newly formed cell plate, and cytokinesis is always completed before the next division ensues. An isobilateral tetrad of microspores is the ultimate product of this controlled and predictable pattern of meiotic divisions.

Several mutants are known to alter the normal progression of meiosis and can be correlated with defects in microtubule distribution. The $d v$ mutation affects the spindle pole organization. The abnormality disrupts microtubule-organizing center structure during the transition between a prophase microtubule array and the metaphase spindle (Staiger and Cande, 1991). Instead of converging to form focused poles, the metaphase spindle poles remain broad as in prometaphase. In the present putative mutation in both Brachiaria hybrids, the phenotypic expressions are similar to those reported in maize, but exhibiting many more details in the second division (Fig. 2). In prometaphase, bivalents are spread in a wide region in the center of the cell (Fig. 2a). Such phenotype is not observed in normal meiocytes. In metaphase I, bivalents are distantly positioned and spread over a large metaphase plate (Fig. 2b). In anaphase $\mathrm{I}$, the segregated chromosomes ascended in parallel, failing to converge into focused poles (Fig. 2c). As a consequence, depending on the distance of chromosomes at the poles, telophase I nuclei were elongated (Fig. 2d), or the chromosomes were grouped into various micronuclei of different sizes (Fig. 2e,f) in each cell. Then the first cytokinesis occurred. In prophase II, the nuclei or micronuclei remained as they were in telophase I (Fig. 2g). However, when there were micronuclei, a second cytokinesis immediately took place dividing the prophase II meiocytes into three (Fig. 2h) or four cells (Fig. 2i), depending on the number of micronuclei formed in telophase I. The amount of chromosomes in each metaphase plate depended on the size of the micronuclei (Fig. 2i). The plate in metaphase II was also broad. In each meiocyte, meiosis progressed to the second division, with sister chromatid segregation not converging into focused poles in anaphase II (Fig. 2j). Slightly elongated nuclei (Fig. 2k), or micronuclei (Fig. 2l), were observed in telophase II. After a third cytokinesis, hexads (Fig. $2 \mathrm{~m}$ ) or octads (Fig. 2n) were formed. Pollen grains of different sizes were generated (Fig. 2o). In the first cytological analysis of one of these hybrids, only two cytokineses occurred and the meiotic products were characterized by tetrads or rare pentads with microspores with several small micronuclei (MendesBonato et al., 2006).

Four classes of actin microfilaments are observed during maize microsporogenesis. A complex network of microfilaments is present during the earliest meiotic stages and persists throughout both divisions. During chromosome segregation and cytokinesis, microfilaments co-distribute with microtubules in the spindle and phragmoplast. In $d v$ mutants using Factin staining, Staiger and Cande (1991) showed that the spindle form is altered, with poles remaining broad and divergent. Shamina (2005) in analyzing a number of processes of the cytoskeletal cycle that participate in spindle formation in higher plant division concluded that the cause of abnormality in the $d v$ mutation is a block in microtubule bundle end convergence at late prometaphase.

In the present hybrids, the number of affected cells varied among them (Table 1). The hybrid HBGC306 presented 4.84\% of affected cells while HBGC348 presented $33.07 \%$. In comparison with the material previously analyzed, hybrid HBGC348 (then named Hb19) showed more affected cells in this study than when first analyzed, i.e. $21.95 \%$ of abnormal cells. In maize, the $d v$ mutation presented $100 \%$ expression and penetrance (Shamina et al., 2000). However, variations in penetrance and expressivity of $d v$ were reported by Clark (1940) and Golubovskaya and Mashnenkov (1981). The phenotypic expressions of $d v$ mutants also varied among different reports (Clark, 1940; Golubovskaya and Mashnenkov, 1981; Staiger and Cande, 1991) when compared with those reported here. In the hybrid HBGC348, the phenotypic expression also varied among the two years of analysis, mainly in the second division. Shamina et al. (2000) proposed that the

Table 1

Phenotypic expression of $d v$ in the Brachiaria hybrids

\begin{tabular}{|c|c|c|c|c|}
\hline \multirow[t]{2}{*}{ Phase } & \multicolumn{2}{|c|}{ HBGC306, R41 × B140/13 } & \multicolumn{2}{|c|}{$\mathrm{HBGC} 348, \mathrm{R} 44 \times \mathrm{B} 140 / 5$} \\
\hline & $\begin{array}{l}\text { No. of cells } \\
\text { analyzed }\end{array}$ & $\begin{array}{l}\text { No. of cells with } d v \\
\text { expression }(\%)\end{array}$ & $\begin{array}{l}\text { No. of cells } \\
\text { analyzed }\end{array}$ & $\begin{array}{l}\text { No. of cells with } d v \\
\text { expression }(\%)\end{array}$ \\
\hline Metaphase I & 486 & $23(4.73)$ & 776 & $65(8.38)$ \\
\hline Anaphase I & 169 & $16(9.47)$ & 209 & $38(18.18)$ \\
\hline Telophase I & 460 & $5(1.09)$ & 394 & $55(13.96)$ \\
\hline Prophase II & 449 & $19(4.23)$ & 482 & $341(70.74)$ \\
\hline Metaphase II & 177 & $14(7.91)$ & 216 & $192(88.89)$ \\
\hline Anaphase II & 28 & $4(14.29)$ & 26 & $22(84.62)$ \\
\hline Telophase II & 151 & $14(9.27)$ & 34 & $26(76.47)$ \\
\hline Tetrad & 537 & $24(4.47)$ & 237 & $46(19.41)$ \\
\hline Total & 2457 & $119(4.84)$ & 2374 & $785(33.07)$ \\
\hline
\end{tabular}


change in morphological phenotype of $d v$ mutants may result from changes in the environmental conditions under which the plants are growing.

For Jenkins et al. (2005), a full and complete understanding of the genetic control of meiosis may be regarded as a means of unleashing desirable and novel genetic variation, or of stabilizing novel combinations of genes in advanced breeding program. Although the abnormal spindle orientation in this hybrid showed a typical maize $d v$ phenotype, we still could not to confirm whether the abnormality is really a mutation. The occurrence in the same hybrid in two different collecting dates reinforces the assumption of a mutation. Both hybrids have different female genitors (B. ruziziensis R41 and R44), but the same male genitor (B. brizantha B140), so they are half-sibs. It is probably the male genitor (B140) which is the depository of the gene, although other hybrids having this same male genitor did not display this abnormality. In all reports about $d v$ maize mutation, pollen fertility was always severely affected because of genome fractionation (Clark, 1940; Golubovskaya, 1979, 1989; Golubovskaya and Mashnenkov, 1981; Staiger and Cande, 1990, 1991; Golubovskaya et al., 1992; Shamina et al., 2000; Shamina, 2005).

The Brachiaria breeding program underway at Embrapa Beef Cattle Center aims at producing superior apomictic hybrids which will breed true for important traits such as forage quality and high dry matter production. Good seed production is also paramount to meet the demand for pastures establishment over large areas and thus assures cultivar adoption. Hybrid HBGC348 is apomictic, which may allow for some seed production since megasporogenesis is independent of meiosis (Araújo et al., 2000). Apomixis in Brachiaria, however, is pseudogamic (Alves et al., 2001), thus seed set will be affected by whatever abnormalities render pollen infertile, compromising endosperm development.

On the other hand, sexual hybrids also play an important role in the program by allowing introgression of desired traits by artificial hybridization. Hybrid HBGC306 is sexual and was selected based on interesting phenotypic traits such as leafiness and high dry matter production. From the present results, however, it should not be used in further crosses due to the high frequency of the putative mutation $d v$ which seriously compromises pollen fertility.

Studies such as those reported here attest to the relevance of cytogenetics in breeding programs, especially when involving interspecific crosses among polyploid genotypes. Time and effort are saved whenever abnormalities such as reported for hybrids HBGC306 and HBGC348 are detected early in the breeding program.

\section{References}

Alves ER, Carneiro CTC, Araújo ACG. Direct evidence of pseudogamy in an apomictic Brachiaria brizantha (Poaceae). Sex Plant Reprod 2001;14: 207-12.

Araújo ACG, Mukhambetzhanov S, Pozzobon MT, Santana EF, Carneiro VTC. Female gametophyte development in apomictic and sexual Brachiaria brizantha (Poaceae). Rev Cytol Biol Veg Bot 2000;23:13-28.

Baker BS, Carpenter ATC, Esposito MS, Esposito RE, Sandler L. The genetic control of meiosis. Annu Rev Genet 1976;10:53-134.

Binarová P, Cenklová V, Hause B, Kubátová E, Lysák M, Dolezel J, et al. Nuclear $\gamma$-tubulin during acentriolar plant mitosis. Plant Cell 2000;12: 433-42.

Chan A, Cande WZ. Maize meiotic spindle assemble around chromatin and do not require paired chromosomes. J Cell Sci 1998;111:3508-15.

Clark FJ. Cytogenetic studies of divergent meiotic spindle formation in Zea mays. Am J Bot 1940;27:547-59.

Endow SA. Microtubule motors in spindle and chromosome motility. Eur $\mathbf{J}$ Biochem 1999;262:12-8.

Golubovskaya IN. Genetic control of meiosis. Int Rev Cytol 1979;58:247-90.

Golubovskaya IN, Mashnenkov AS. Genetic control of chromosome segregation during the first meiotic division. Maize Genet Coop News Letter 1981;55:78-81.

Golubovskaya IN. Meiosis in maize: $m e i$ genes and conception of genetic control of meiosis. Adv Genet 1989;26:149-92.

Golubovskaya IN, Avalkina NA, Sheridan WF. Effects of several meiotic mutations of female meiosis in maize. Dev Genet 1992;13:411-24.

Gottschalk W, Kaul MLH. The genetic control of microsporogenesis in higher plants. Nucleus 1974;17:133-66.

Gottschalk W, Kaul MLH. Asynapsis and desynapsis in flowering plants. I. Asynapsis. Nucleus 1980a;23:1-15.

Gottschalk W, Kaul MLH. Asynapsis and desynapsis in flowering plants. II. Desynapsis. Nucleus 1980b;23:97-120.

Jenkins G, Mikhailova EI, Langdon T, Tikholiz OA, Sosnikhina SP, Jones RN. Strategies for the study of meiosis in rye. Cytogenet Genome Res 2005; 109:221-7.

Mendes-Bonato AB, Pagliarini MS, Valle CB. Abnormal spindle orientation during microsporogenesis in an interspecific Brachiaria (Gramineae) hybrid. Genet Mol Biol 2006;29:122-5.

Pagliarini MS, Freitas PM, Takayama SY, Batista LAR. An original meiotic mutation in Paspalum regnellii. Sex Plant Reprod 1998;11:17-21.

Shamina N, Dorogova N, Trunova S. Radial spindle and the phenotype of the maize meiotic mutant, $d v$. Cell Biol Int 2000;24:729-36.

Shamina NV. A catalogue of abnormalities in the division spindles of higher plants. Cell Biol Int 2005;29:384-91.

Staiger CJ, Cande WZ. Microtubule distribution in $d v$, a maize meiotic mutant defective in the prophase to metaphase transition. Dev Biol 1990;138: 231-42.

Staiger CJ, Cande WZ. Microfilament distribution in maize mutants correlates with microtubule organization. Plant Cell 1991;3:637-44.

Taschetto OM, Pagliarini MS. Description of a new type of meiotic abnormality in maize (Zea mays L.). Maydica 1993;38:47-50.

Wilson ZA, Yang C. Plant gametogenesis conservation and contrasts in development. Reproduction 2004;128:483-92.

Young BA, Sherwood RT, Bashaw EC. Cleared-pistil and thick-sectioning techniques for detecting aposporous apomixis in grasses. Can J Bot 1979; $57: 1668-72$. 